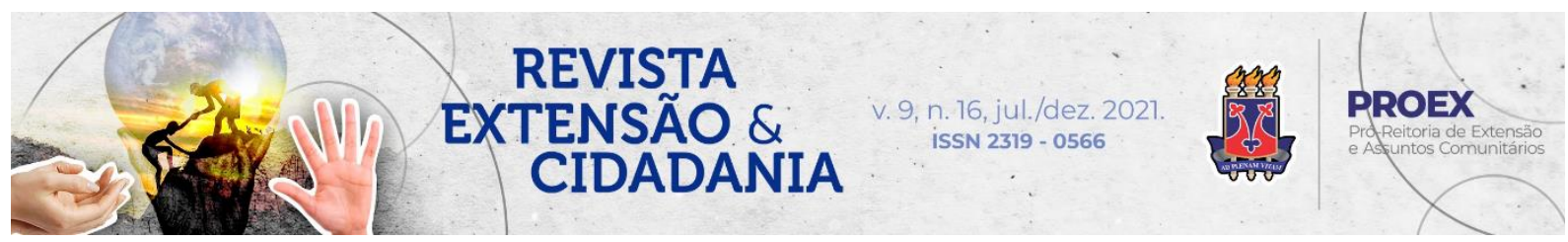

DOI: 10.22481/recuesb.v9i16.9581

\title{
O TEATRO EM PRIVAÇÃO DE LIBERDADE: RELATO SOBRE A FORMAÇÃO DE UMA REDE
}

\section{THE THEATER IN DEPRIVATION OF LIBERTY: A REPORT ON THE FORMATION OF A NETWORK}

\section{EL TEATRO EN PRIVACIÓN DE LIBERTAD: INFORME SOBRE LA FORMACIÓN DE UNA RED}

\author{
Laís Jacques Marques ${ }^{1}$ \\ Vicente Concilio ${ }^{2}$
}

\begin{abstract}
Resumo: O presente escrito propõe um relato de experiência sobre a união de três universidades que realizam atividades teatrais em espaços de privação de liberdade. São elas a Universidade de Michigan (UM), a Universidade do Estado de Santa Catarina (UDESC) e a Universidade Federal do Estado do Rio de Janeiro (UniRio). O objetivo do artigo é evidenciar os avanços, desafios e descobertas realizadas a partir da união das ações realizadas pelas três instituições. Dividido em três seções, na primeira, abordamos quais caminhos cada instituição percorreu até que se encontrassem. Na segunda, o que tal encontro propiciou para o desenvolvimento das práticas em espaços de privação de liberdade e, na seção final, como conclusão, discorremos sobre as atividades atuais da rede e o que delas nos alimenta para seguirmos na busca pela inclusão do teatro em contextos prisionais e socioeducativos.
\end{abstract}

Palavras-chave: Teatro e Prisão. Pedagogia. Privação de Liberdade. Sistema Socioeducativo.

Abstract: This paper proposes an analysis of the experiences of three universities that carry out theater activities in spaces deprived of freedom. They are the University of Michigan (Universidade de Michigan), the University of the State of Santa Catarina (UDESC) and the Federal University of the State of Rio de Janeiro (UniRio). The objective of the article is evidence the advances, challenges and discoveries made from the union of actions carried out by the three institutions. Divided into three sections, the first one will discuss which paths each institution took until they met. In the second, what this meeting allowed for the development of practices in spaces of deprivation of freedom and, in the final section, as a conclusion, we discuss the current activities of the network and what, from them, feeds us to continue in the search for the inclusion of the theater in prison and socio-educational contexts.

Keywords: Theater and Prison. Pedagogy. Deprivation of Liberty. Socio-educational System.

\footnotetext{
${ }^{1}$ Atriz e professora de teatro. Doutoranda em Teatro, pela Universidade do Estado de Santa Catarina (UDESC), Gravataí, Rio Grande do Sul, Brasil. Orcid: https://orcid.org/0000-0001-5554-4177 E-mail: laisjacquesm@gmail.com

${ }^{2}$ Ator, diretor e professor de teatro. Doutor em Teatro, pela Universidade de São Paulo (USP). Professor de Teatro do Programa de Pós-Graduação em Teatro, da Universidade do Estado de Santa Catarina (UDESC), Florianópolis, Santa Catarina, Brasil. Orcid: https://orcid.org/0000-0003-2897-1581 E-mail: viconcilio@gmail.com
} 
Resumen: Este artículo propone un análisis de las experiencias de tres universidades que realizan actividades teatrales en espacios privados de libertad. Son la Universidad de Michigan (UM), la Universidad del Estado de Santa Catarina (UDESC) y la Universidad Federal del Estado de Río de Janeiro (UniRio). El objetivo del artículo es evidencia los avances, desafios y descubrimientos de la unión de acciones llevadas a cabo por las tres instituciones. Dividido en tres secciones, en la primera discutiremos qué caminos tomó cada institución hasta que se conocieron. En el segundo, lo que permitió este encuentro para el desarrollo de prácticas en espacios de privación de libertad y, en el último apartado, como conclusión, comentamos las actividades actuales de la red y lo que, a partir de ellas, nos alimenta para continuar en el buscar la inclusión del teatro en contextos penitenciarios y socioeducativos.

Palabras-clave: Teatro y Prisión. Pedagogía. Privación de libertad. Sistema socioeducativo.

\section{Preâmbulo}

Neste escrito, relatamos parte de nossa história enquanto rede de pessoas que atuam em espaços de privação de liberdade através de programas de extensão e de pesquisa vinculados a três Universidades. São elas a Universidade de Michigan (UM), a Universidade Federal do Estado do Rio de Janeiro (UniRio) e a Universidade do Estado de Santa Catarina (UDESC).

Em três seções, iniciamos o relato no objetivo de evidenciar o trajeto que percorreram tais instituições até que seus caminhos se cruzem. Na segunda parte, compartilhamos o que cada uma realizou e realiza atualmente e o que, de tais ações, convergiram para a formação de um grupo. Por fim, apontamos quais aspectos reverberam em nossas práticas artísticas e pedagógicas, além de cotejar as transformações dos modos com que nos percebemos e nos relacionamos a partir da perspectiva da privação de liberdade.

De modo breve, pois aprofundaremos nosso histórico a seguir, em curtas linhas é possível afirmar que nossa história começou oficialmente em 1995, ano em que uma das três Universidades componentes da teia que aqui será apresentada registrou, academicamente, suas atividades teatrais em prisões. Nos referimos ao Prison Creative Arts Project (PCAP), potente projeto extensionista da Universidade do Michigan. Atualmente, o PCAP é considerado entre pessoas estudiosas da temática das artes em privação de liberdade como a maior organização de práticas artísticas em prisões do mundo.

Se por um lado, os Estados Unidos é o país com maior índice de pessoas privadas de liberdade mundialmente, conforme o levantamento do Institute for Crime \& Justice Research (ICPR), que apontou 2,1 milhões de pessoas presas nos EUA no ano de 2020, o Brasil ocupa já o

Revista Extensão \& Cidadania, v. 9, n. 16, p. 242-252, jul./dez. 2021. 
terceiro lugar no ranking. Aqui, faz-se necessário mencionar a demora de nosso país frente à adesão da abolição da escravidão, sendo o último das Américas a admitir liberdade para pessoas que foram escravizadas ao longo do dito processo civilizatório nacional. A nosso ver, muito mais de 500 anos refletem no cenário que o Brasil vivencia quando o assunto é cárcere (BORGES, 2019).

No Brasil, é, em 1997, que a Universidade Federal do Estado do Rio de Janeiro (UniRio) passa a atuar em prisões, o projeto nasce e se mantém em caráter extensionista nos presídios do estado. Entretanto, é necessário dizer que há registros do teatro sendo feito em prisões nacionais muito anteriores ao período em que iniciam o projeto. Parte do histórico do teatro realizado em prisões em nosso país é investigado por uma das coordenadoras do projeto de pesquisa e extensão Observatório de práticas artísticas no cárcere e em espaços de privação de liberdade, a Profa. Dra. Viviane Narvaes. A teatróloga pesquisou o Teatro do Sentenciado, criado por Abdias do Nascimento (1914 - 2011), no período em que o mesmo esteve preso (NARVAES, 2020). Para não alterarmos em demasia a rota de nosso relato, voltemos às conexões que nos transformaram em grupo.

Em 2017, outro importante feito une a UDESC às duas Universidades supracitadas, o ano marca o ingresso de práticas teatrais na cidade de Florianópolis, em Santa Catarina, a partir do projeto de pesquisa e extensão Teatro e Prisão: Infiltrações das Artes Cênicas em Espaços de Vigilância, coordenado pelo Prof. Dr. Vicente Concilio. Aqui, faz-se relevante apontar que também passamos a atuar no sistema socioeducativo da mesma cidade, já no ano de 2019, como mais uma ação desenvolvida pelo projeto.

Nosso encontro foi e é propulsor de ações que reverberam não só na prática pedagógica do teatro, mas na tarefa de respaldar direitos muitas vezes negados a quem passa por privação de liberdade. É a partir desse fértil encontro entre programas de extensão e pesquisa que iniciamos a exposição de nosso relato.

\section{Sobre a rede}

Há, portanto, esses acontecimentos que cresceram, que cresceram como se diz de uma árvore que ela cresce ou das paredes da casa que elas sobem; há redes que se tecem e se tramam, como tantas teias de aranha na bifurcação dos galhos ou nos recantos; ainda que passem os pássaros e a vassoura da dona da casa. (DELIGNY, 2015, p. 16)

Revista Extensão \& Cidadania, v. 9, n. 16, p. 242-252, jul./dez. 2021. 
O pedagogo francês Fernand Deligny (1913 - 1996), na obra O aracniano e outros textos (2015) faz jus ao nosso entendimento de rede ao relatar o que mobilizou suas pesquisas com crianças autistas em conflito com a lei na França. Deligny foi diretor de um centro de observação para crianças autistas e, segundo consta em investigações realizadas pela pesquisadora brasileira Sônia Regina da Luz Matos (2017), é possível analisar seu trabalho em duas fases. A primeira, em que o autor atuou por mais de dez anos em institutos correcionais e a segunda em que, desvinculado dos centros, criou um instituto próprio de descobertas artísticas, intituladas por ele como cartografias aracnianas (DELIGNY, 2015), com as crianças e jovens "desadaptadas/os" a que atendia.

Deligny ampliou o conceito de rede a partir do viés aracnídeo e, ao criar sua cartografia aracniana, engendrou estabelecer novas linhas, de fugas dos preconceitos sociais, mas principalmente de expressões, para a descoberta da potência inventiva de jovens autistas que, dado o contexto de miséria fruto da primeira guerra mundial que a França enfrentava, poucas alternativas de sobrevivência possuíam, para Deligny (2015, p.15), "A rede é um modo de ser" O centro que o pedagogo criou abrigava não só jovens autistas, mas seus familiares e a comunidade ao redor do local. Estes realizavam tarefas como preparar refeições, conservar o espaço físico e ensinar seus ofícios aos jovens, que, ali, tinham liberdade para sair, trabalhar ou se divertir e retornar quando quisessem ao centro. Gradualmente, Deligny desenvolveu uma pedagogia amparada no convívio da juventude autista em conflito com a lei e a sociedade, objetivando o contrário do que fazem os centros de internações, que os apartam do convívio social.

Já que compreendemos os liames componentes da rede como uma ação metodológica de apoio mútuo, pedagógico e social, se faz necessário, a nosso ver, compreender como tal teia se iniciou para que saibamos de forma e para que lado tecer mais e melhor nosso emaranhado trabalho. O questionamento quanto às origens da teia que tecemos é novamente despertado por influência de Deligny que diz:

Seduzido por essa palavra - aracniano -, fui procurar a aranha como termo de uma analogia. O inconveniente dessa escolha é que a aranha não é social; é solitária, e sua obra, ela a realiza sozinha, enquanto formigas, cupins e outros trabalham em coro; assim também, o homem. Por mais semelhante que seja a teia de aranha, a rede é obra de alguns, e uns mais uns são vários, sem que seja possível, como quando se trata dos cupins trinervitermes, identificar o mestre de obras que teria tido o projeto em gestação em sua cabeça, sua alma ou se coração. (DELIGNY, 2015, p. 24)

Revista Extensão \& Cidadania, v. 9, n. 16, p. 242-252, jul./dez. 2021. 
Sendo impossível, segundo a perspectiva de Deligny (2015), encontrar um "mestre de obras" de uma rede, nos interessa compreender, nesse primeiro movimento propiciado pelo desejo coletivo de tecer juntas/os, unir nossos fios, como se deu a busca por fortalecer a trama que criamos, enquanto educadoras/es de teatro em espaços de privação de liberdade.

Começamos pelas ações desenvolvidas (ou tramadas) por quem se encontra mais distante - no quesito geográfico - das práticas pedagógicas de teatro brasileiras, principalmente para que seja visível a linha do tempo de nossas ações até a chegada na formação de um grupo. O movimento iniciado pela teatróloga estadunidense Ashley Lucas enquanto diretora do PCAP abrangeu realizar amplo levantamento mundial do histórico do teatro em prisões. Na obra Teatro em prisões e a crise global do encarceramento, de Lucas (2021), além de ter relatado como chegou até a temática da arte atrás das grades, presenciou apresentações e oficinas teatrais em presídios do mundo e entrevistou participantes e seus familiares. De suma relevância a quem se dedica ao tema, a obra é rica na medida em que nos permite o acesso às opções metodológicas de trabalhos desenvolvidos mundo a fora.

Dentre as ações do PCAP, sabe-se, a partir do capítulo do livro A busca do comum práticas artísticas para outros futuros possíveis (CRUZ; CRUZ; BEZELGA; FALCÃO e AGUIAR, 2019), intitulado Avançamos juntos - um programa de intercâmbio sobre teatro nas prisões entre três universidades, escrito por Lucas, Natália Fiche (uma das coordenadoras do grupo de teatro nas prisões da UniRio) e Concilio, que "o PCAP oferece atividade artística para adultos em todas as vinte e seis prisões estatais e uma prisão federal em Michigan, em duas instalações para jovens e em uma comunidade de habitação pública" (LUCAS; FICHE; CONCILIO, 2019, p. 131). De acordo com o estudo, um dos objetivos centrais do PCAP é desenvolver autonomia nos processos artísticos de quem participa das oficinas.

Lucas assumiu a direção do PCAP no ano de 2013, a convite da Universidade de Michigan, a partir daí, criou duas matérias no centro de artes em que leciona. Uma delas, intitulada Teatro e Encarceramento, tornar-se-ia obrigatória a quem desejasse fazer parte do "Programa de Intercâmbio do PCAP com o Brasil - uma aula de estudos no exterior na qual os estudantes da Universidade de Michigan recebem créditos através do Departamento de Teatro e Drama por seu trabalho com parceiros nas universidades brasileiras" CRUZ; CRUZ; BEZELGA; FALCÃO e AGUIAR, 2019, p. 13). Dá-se então, em 2013, um forte laço em nossa trama.

Revista Extensão \& Cidadania, v. 9, n. 16, p. 242-252, jul./dez. 2021. 
Aqui, nossa rede se emaranha, sobre a participação de estudantes da Universidade de Michigan no Rio de Janeiro, faz-se necessário apresentar o surgimento do teatro realizado pela UniRio como projeto de extensão. Fundado por Fiche e Maria de Lourdes Naylor Rocha, a partir da visita ao Brasil de Paul Heritage, em junho de 1997, o Departamento de Artes da Universidade decidiu consolidar o trabalho de teatro em prisões como parte de uma atividade de extensão. Lucas, Fiche e Concilio (2019) explicaram que para que as oficinas realizadas pelos grupos em prisões do estado ocorram, é necessária a condução de oficinas introdutórias, prévias, ministradas pelo curso de graduação às pessoas que irão mediar ações nos presídios. Assim, compreende que, além de preparar estudantes para o campo, fortalecem o contato enquanto grupo formador da rede. Ainda, para Lucas, Fiche e Concilio (2019, p. 132), "O trabalho nas prisões não têm interesse em conhecer os crimes cometidos pelos participantes. $\mathrm{O}$ único foco é o teatro". A partir dessa perspectiva, é que se dá, também, os trabalhos desenvolvidos pelas demais instituições.

A parceria entre Universidade de Michigan e UniRio ocorreu mediante a proposta feita pelo Prof. Dr. Renato Icarahy, então chefe do Departamento de Direção da UniRio. Na ocasião, Icarahy propôs a Lucas que levasse estudantes da Universidade de Michigan durante os próximos três anos (portanto de 2013 até 2016), a visitas longas ao Rio de Janeiro para que pudessem conhecer as unidades prisionais em que a UniRio ministrava oficinas, além de estabelecer relações e trocas quanto aos ensinos e práticas referentes ao teatro feito em prisões entre as/os estudantes das duas Universidades.

Assim também se aproximou o grupo de teatro em prisão da UDESC, terceira Universidade a somar na construção da rede que UniRio e Universidade de Michigan teciam. Concilio, coordenador do projeto Teatro e Prisão da UDESC, realizou como pesquisa de mestrado um trabalho de inegável relevância a quem se dedica a pensar e fazer teatro entre grades. Referência nacional, a obra Teatro e prisão: dilemas da liberdade artística (CONCILIO, 2008) é a primeira a abordar a temática do teatro feito em prisões nacionais. Na pesquisa, refletem-se os processos de montagens teatrais e apresentações realizadas com atrizes, atores e pessoas em privação de liberdade na cidade de São Paulo.

Entre ações espaçadas no Presídio Feminino de Florianópolis - SC sob a coordenação de Concilio, realizadas e interrompidas desde 2013, é, em 2017 e a partir do contato com o Centro Ciências Humanas e Educação (FAED) da UDESC, que as atividades ganham maiores proporções. O ano marcou o $1^{o}$ Seminário Internacional de Educação Artística e Prisional e

Revista Extensão \& Cidadania, v. 9, n. 16, p. 242-252, jul./dez. 2021. 
contou com palestras de Lucas e Fiche. A repercussão do evento e as falas das palestrantes que enalteceram os avanços e conquistas do teatro quanto à melhoria da expressão de pessoas em situação de cárcere - engajaram a coordenadoria do Presídio Feminino de Florianópolis $\mathrm{SC}$, que, a partir dali, firmou compromisso em permitir e manter as oficinas de teatro na unidade prisional.

A partir do relato sobre a inserção do trabalho da UDESC no presídio Feminino em Florianópolis - SC, é possível refletir que a criação da rede possibilitou ampliar o debate sobre a arte em contextos prisionais, o que auxiliou imensamente na permanência e divulgação do projeto. A credibilidade dada por intermédio da palestra de Lucas e Fiche foram propulsoras do trabalho extensionista e de pesquisa que a UDESC desenvolve até hoje.

\section{Os nós da rede}

Acreditamos que os grupos de afinidade trabalhados em rede geram o apoio mútuo. Semelhante esteio notamos nas palavras de Lucas, Fiche e Concílio (2019), quando se referem ao intercâmbio entre as universidades brasileiras. Segundo os autores:

\footnotetext{
A oportunidade de viajar atraiu novos estudantes para o programa que, de outra forma, nunca teriam ouvido falar do PCAP, trazendo-os, portanto, para o trabalho que fazemos nas prisões de Michigan. Muitos participantes do PCAP relatam que suas experiências no Brasil os ajudaram a entender melhor as lutas pela justiça social e as prisões em um sentido mais amplo. (LUCAS, FICHE; CONCILIO, 2019, p. 133)
}

Neste relato, é possível observar que não foi só no Brasil que a união entre as Universidades se mostrou profícuas, os diferentes desafios de se trabalhar teatro dentro de prisões em Michigan se comparados ao contexto brasileiro. Lucas, em suas palavras, "Nós, de Michigan, passamos boa parte do nosso tempo no Brasil surpresos com o quanto nossos colegas da UniRio e da UDESC realizam com tão pouco apoio de suas universidades" (LUCAS, FICHE, CONCILIO, 2019, p. 133). Segundo Lucas, se por um lado, em Michigan, o controle por parte das administrações penitenciárias durante as aulas do PCAP é mais rígido, aqui, o desafio se dá tanto no campo da segurança (pois, mesmo que menos, também somos vigiadas durante as práticas) quanto ao incentivo para que façamos nosso trabalho. Os apoios financeiros, quando existem, são muito menores do que os que recebem estudantes da

Revista Extensão \& Cidadania, v. 9, n. 16, p. 242-252, jul./dez. 2021. 
Universidade de Michigan. Isso se dá porque não há fomento para atender aos programas de extensão do Brasil, realidade oposta à vivenciada por Lucas nos EUA.

Conforme já apontado anteriormente no texto escrito em parceria Lucas, Fiche e Concilio (2019), se são pouco valorizados os trabalhos artísticos realizados em cenário nacional, a precariedade de efetuá-los em penitenciárias no Brasil tornou-se evidente:

\begin{abstract}
Infelizmente, tanto os projetos de Florianópolis quanto do Rio de Janeiro estão fortemente ligados à iniciativa pessoal dos professores, faltando apoio institucional e recursos necessários para apoiar o trabalho de arte e educação nas penitenciárias. A precariedade orçamentária das universidades públicas brasileiras é responsável por parte dessa dificuldade. No entanto, conhecer a estrutura e as estratégias desenvolvidas pelo PCAP alimenta nossos sonhos e pode inspirar a construção de propostas semelhantes no Brasil. (LUCAS; FICHE; CONCILIO, 2019, p. 133)
\end{abstract}

Os exemplos vivenciados na prática por parte de estudantes brasileiros que puderam visitar a sede do PCAP serviram de motivação para seguirmos na luta por infiltrar nossa arte em prisões nacionais. E seguirá servindo até que, em algum momento, avancemos e vençamos a precariedade com que nosso trabalho é encarado por parte das autoridades nacionais.

Sobre o intercâmbio entre Universidade de Michigan, UniRio e UDESC, percebemos que "A prisão brasileira é tudo que esperamos em um país em crise: uma sucessão de ausências. Falta de dinheiro, falta de espaço, falta de apoio. Mas quando o grupo se reúne para as aulas, com a vontade de que algo aconteça, o teatro emerge com força" (LUCAS, FICHE, CONCILIO, 2019). É esta força que nos referimos e que nos agarramos para seguirmos em luta, não só para mantermos nosso trabalho em ação nas unidades em que atuamos, mas para que consigamos avançar enquanto sociedade.

Tal força, emergente da prática teatral realizada em prisões, se faz presente em todos os fios que compõe nossa rede, fios estes que se fortalecem na medida em que cruzamos nossos caminhos, como num nó cego. Fiche (2019) também se ampara nessa trama e acredita nas possibilidades que a união do grupo permite. Para a autora:

Esse intercâmbio nos levou a lançar um olhar diferente sobre nosso próprio projeto e a compreender suas qualidades fundamentais. Vemos novas possibilidades de ação em nosso próprio contexto social e político. [...] Os estudantes da UniRio dizem que essa experiência os fez sentir que o mundo é muito maior do que imaginaram. Ao mesmo tempo, torna-os conscientes de que existem outras pessoas compartilhando os mesmos ideais que os deles,

Revista Extensão \& Cidadania, v. 9, n. 16, p. 242-252, jul./dez. 2021. 
buscando melhorar as vidas daqueles que são excluídos ou menos privilegiados, devido às mais diversas circunstâncias, trazendo amor e sorrisos para aqueles que deles necessitam e oferecendo educação e respeito. Esse sentimento de que compartilhamos propostas artísticas similares com pessoas em outro país fortalece nosso trabalho. (LUCAS; FICHE; CONCÍLIO, 2019, p. 134)

Há, a partir do intercâmbio, a ampliação da sensação de não estarmos sós na luta pelo acesso à arte e pelo desencarceramento. Além disso, a partir dele é possível facilitar as trocas para o aprofundamento de nossas práticas. O movimento retroalimentar que a rede proporciona amplia nossas potências e ações, engendra espaços de trocas e de compartilhamentos. Coletivamente, expomos as angústias que vivemos e que costumeiramente deixamos guardadas em nossa rotina para que não atravessem conosco os muros da prisão, uma vez que nossa premissa para o trabalho é a de levar alegria para a rotina institucional, marcada pela rigidez e pela vigilância.

Retomando o pensamento de Deligny (2020, p. 52), agora em Semente de crápula conselhos aos educadores que gostariam de mantê-la, "Se estiverem trancafiados, tudo o que você pode fazer por eles é trazer-lhes três brotinhos de grama fresca, como faz aquela velha que vem dar uma olhada em seus coelhos na gaiola: bela história, projetos, músicas de caminhada... Mas isso jamais será carne de primeira". Sabemos nossas limitações enquanto pessoas que engendram levar arte para trás das grades, mas, se nossa tarefa é essa, a de fazer com que o tempo de quem está privada/o de liberdade passe de modo menos doloroso do que corriqueiramente os são, que o façamos! Quem sabe, assim, nos tornemos socialmente mais tolerantes com as diferenças e resolvamos nossos dilemas estruturais de outro modo?

\section{Considerações que não findam}

Atualmente, tendo em vista os riscos de aglomerações ou contatos físicos que a pandemia da Covid-19 pode ocasionar, temos nos encontrado (ministrantes das oficinas e demais interessadas/os na temática das artes em privação de liberdade), de modo virtual e semanalmente, para lermos e debatermos textos que dialoguem com nossas ações. No ano de 2020 fora publicado o dossiê Artes da cena atrás das grades, pela revista de estudos em artes cênicas Urdimento, da UDESC (URDIMENTO, 2020). Nele constam textos escritos por mais de quarenta pessoas que colaboraram com relatos de experiências de artes vivas realizadas em

Revista Extensão \& Cidadania, v. 9, n. 16, p. 242-252, jul./dez. 2021. 
sistemas de privação de liberdade. Os estudos que realizamos a partir dos escritos presentes no dossiê nos auxiliaram na tarefa de ampliar a rede iniciada em 2013.

Em outubro de 2021, retomamos virtualmente nossa oficina de teatro no sistema socioeducativo da cidade de Florianópolis, no Centro de Internação Feminina (CIF). Nove jovens em privação de liberdade participam semanalmente dos encontros, que marcados por risadas, momentos de descontração e de escuta, como bem se pretendem nossas ações.

Objetivamos com o escrito relatar o histórico que uniu nossas ações extensionistas e teatrais em espaços de privação de liberdade. Amparamo-nos no pensamento de Deligny (2015, 2020) a respeito das noções de rede e de teia propiciadas pela experiência do autor com jovens autistas em conflito com a lei pois identificamos, nelas, propulsões de liberdade que almejamos atingir com as pessoas privadas de liberdade que encontramos ao longo de nossas atividades. Através da união entre as Universidades e, dada às descobertas que apresentamos ao longo do texto, as palavras de Lucas se fazem pertinentes. Parece-nos que as palavras dela contemplam o que almejamos expor ao longo do texto:

Que milagres o teatro pode nos proporcionar! Nós estávamos alheios ao fato de que éramos vigiados por uma câmera ou rastreados por monitores. Como no Brasil ou em qualquer lugar do mundo, foi assim que aconteceu em Michigan; o teatro nos permite separar o nosso sentimento de aprisionamento. (LUCAS; FICHE; CONCÍLIO, 2019, p. 134)

O sentimento de liberdade é deslocado do conceito de liberdade (que sabemos não ser uníssono, pois é mais um dos conceitos abstratos que pairam em nossa sociedade, mas que, no contexto de privação de liberdade, se faz extremamente material). Tal entendimento é apresentado em nosso relato a partir do olhar das artes vivas, conforme relatado por Lucas (LUCAS; FICHE; CONCÍLIO, 2019). No contexto se engendra, a partir do trabalho promulgado pela rede que tecemos, acima de tudo, a expressão.

Para além de expor os modos pelos quais encontramos reforço na tarefa de promulgar a relevância de nossas ações, com o escrito, propomos também a ampliação da rede de pessoas que atuam com teatro em ambientes de privação ou restrição de liberdade. Desejamos que nossos registros não cessem por aqui e que possamos, a cada encontro, reforçar o compromisso de infiltrar ações artísticas nos locais que costumeiramente nos são negados o acesso. $\mathrm{O}$ escrito é também um convite para compor a rede. Sempre em aberto. Sempre possibilidades de aprendizados e de apoio mútuo.

Revista Extensão \& Cidadania, v. 9, n. 16, p. 242-252, jul./dez. 2021 


\section{Referências}

BORGES, Juliana. Encarceramento em massa. São Paulo: Sueli Carneiro; Pólen, 2019.

CONCILIO, Vicente. Teatro e Prisão: dilemas da liberdade artística. São Paulo: Hucitec, 2008.

CRUZ, Carla; CRUZ, Hugo; BEZELGA, Isabel; FALCÃO, Miguel; AGUIAR, Ramon (org.). A busca do comum - práticas artísticas para outros futuros possíveis. Porto: i2ADS Instituto de Investigação em Arte, Design e Sociedade, 2019.

DELIGNY, Fernand. O aracniano e outros textos. Trad. Lara de Malimpensa. São Paulo: N1 Edições, 2015.

DELIGNY, Fernand. Semente de crápula: conselhos aos educadores que gostariam de cultivá-la. São Paulo: N-1 edições, 2020.

LUCAS, Ashley E. Teatro em prisões e a crise global do encarceramento. São Paulo: Hucitec, 2021.

LUCAS, Ashley E.; FICHE, Natália; CONCILIO, Vicente. Avançamos juntos — um programa de intercâmbio sobre teatro nas prisões entre três universidades. In: CRUZ, Carla; CRUZ, Hugo; BEZELGA, Isabel; FALCÃO, Miguel; AGUIAR, Ramon (org.). A busca do comum - práticas artísticas para outros futuros possíveis. Porto: i2ADS - Instituto de Investigação em Arte, Design e Sociedade, 2019. p. 130-136.

MATOS, Sônia Regina da Luz. Os educadores franceses Célestin Freinet e Fernand Deligny. Revista Ibero-Americana de Estudos em Educação, Araraquara, v. 12, n. 4, p. 2231-2244, 2017.

NARVAES, Viviane Becker. Contribuições para uma história do teatro nas prisões do Brasil. Urdimento - Revista de Estudos em Artes Cênicas, Florianópolis, v. 3, n. 39, p. 1-29, 2020. Disponível em: https://www.revistas.udesc.br/index.php/urdimento/article/view/18847. Acesso em: 6 nov. 2021.

URDIMENTO - Revista de Estudos em Artes Cênicas. Dossiê Temático: Artes da cena atrás das grades, v. 3 n. 39, dez. 2020. Disponível em:

https://www.revistas.udesc.br/index.php/urdimento/issue/view/788. Acesso em: 18 out. 2021.

Recebido: 30.09.2021

Aceito: 07.11.2021

This work is licensed under a Creative Commons Attribution 4.0 International License.

Este trabalho está licenciado com uma Licença Creative Commons - Atribuiç̃ão 4.0

Revista Extensão \& Cidadania, v. 9, n. 16, p. 242-252, jul./dez. 2021.

ISSN 2319-0566 DOI: 10.22481/recuesb.v9i16.9581 